\title{
Comparison of small and high volume sample inoculation of fungal media with routine bacterial culture media for improved yield of mold from sputa
}

\author{
Ghazala Jabeen, Salima Rattani, Joveria Farooqi, Kauser Jabeen \\ Department of Pathology and Laboratory Medicine, Section of Clinical Microbiology, Aga Khan University, Karachi, Pakistan
}

\section{Objectives}

Patients with productive cough who request sputum cultures frequently have symptoms refractory to empiric therapy with antibiotics and inhaled or systemic steroids. Underlying conditions predispose them to a wide-spectrum of mold infections, usually missed on routine bacterial cultures. Most physicians overlook the importance of requesting additional fungal cultures, delaying diagnosis. This study was conducted to compare small and high volume sample inoculation of sputa on fungal media with standard bacterial cultures for improved yield of molds.

\section{Methods}

- Sputum samples from 41 adults, (age range: $17-81$ y, $41.4 \%$ females) submitted to Aga Khan Clinical Laboratories in January 2018 were assessed for quality using gram stain criteria of pus to epithelial cell ratio of $>10: 1$.

- Representative samples were processed for routine bacterial culture on Sheep Blood Colistin Nalidixic Agar (BCNA), Chocolate Agar (CHOC) and MacConkey agar.

- In parallel for the comparison study: a loopful of the purulent part (small volume) on Sabouraud's Dextrose Agar (SDA) and Potato Dextrose Agar (PDA), and $1 \mathrm{ml}$ (high volume) on SDA.

- All culture plates were incubated at $35 \pm 1^{\circ} \mathrm{C}$ for 5 days. Patient information collected in the course of clinical reporting of culture, and yield of mold on type of processing was recorded.

Frequencies of underlying co-morbids and mold isolation were computed.

\section{Results}

- Out of 41 specimens assessed, 36 (87.8\%) samples yielded mold by any method. Thirteen were positive and 5 negative for fungal growth by all 3 methods; 15 specimens on both small and high volume fungal cultures, but not routine bacterial, and additional 8 yielded mold only on high volume sample inoculation. (Figure)
- Clinical history was available on 26 patients: $46 \%$ patients were on systemic or inhaled steroids, $42 \%$ on antibiotics and $31 \%$ had an underlying lung disease. Sixteen (61.5\%) patients presented with symptoms of less than 2 weeks' duration. In patients with asthma, both high and low volume fungal cultures had a yield of $88 \%$, while only $33 \%$ bacterial culture grew mold (Table).

- The predominant molds isolated were Aspergillus flavus (83\%), $A$. niger (64\%), Penicillium spp. (8\%), A. fumigatus (5.5\%).

- High volume inoculation yielded mold at 1.6 (Cl: $0.4-2.8)$ days of incubation, low volume fungal culture 1.9 (0.5-3.3) days and bacterial culture $2.6(0.7-4.5)$ days $(p=0.0001)$

\section{Conclusion}

High volume sputum inoculation had the highest yield of mold compared to small volume fungal culture and routine bacterial culture, with small volume fungal culture still performing better than routine culture. High volume sample inoculation can give improved and rapid fungal yield in patients suspected of pulmonary fungal infections.

Figure. Difference in low and high volume inoculation of the same sputum sample.

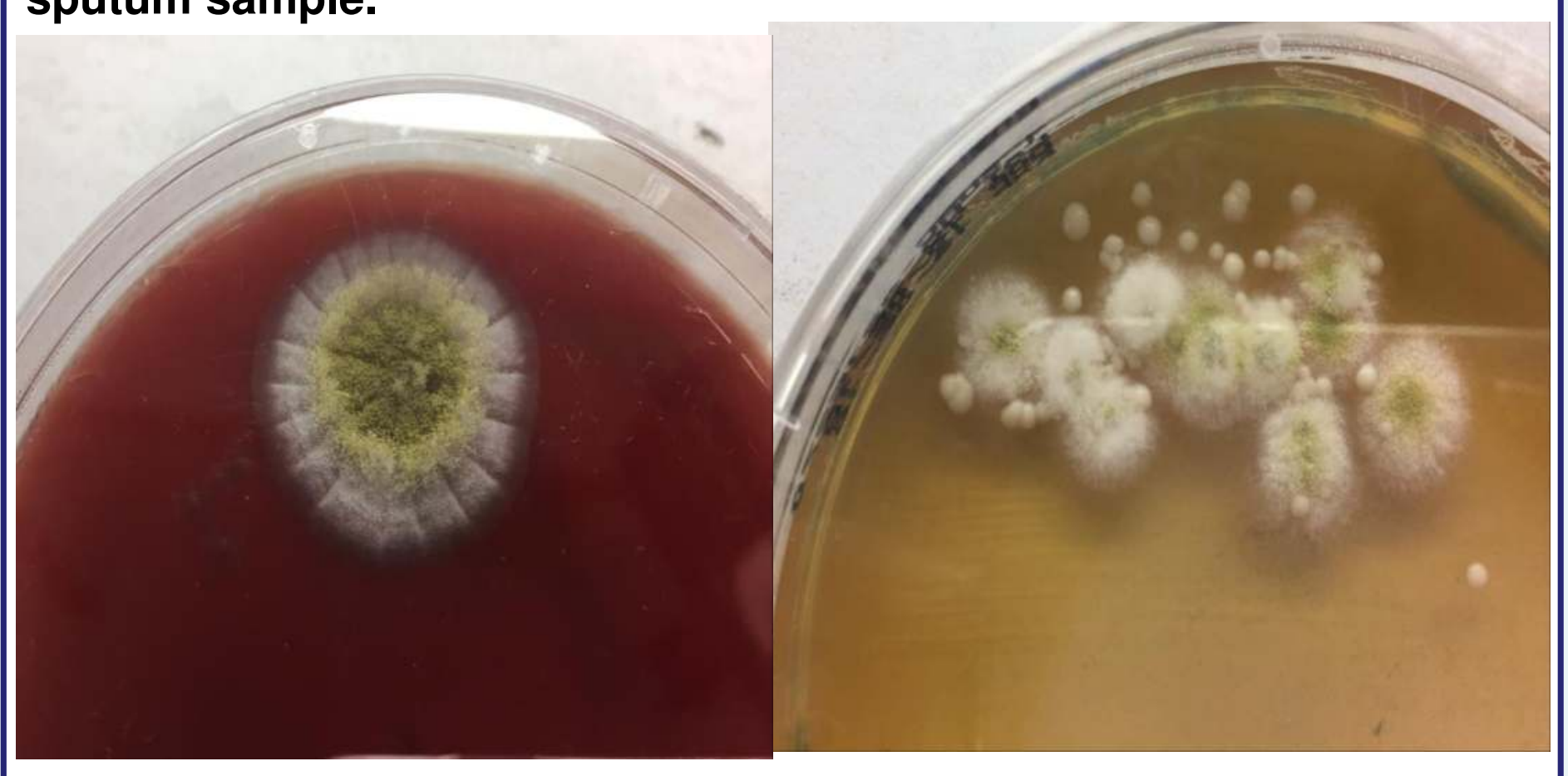

Blood agar plate on the left was inoculated with a loopful of the purulent part (small volume), while SDA on the right was inoculated with $1 \mathrm{ml}$ of same sputum sample. Single colony of mold could easily have been dismissed as a contaminant but appearance of culture on SDA would be convincing of the significance of the mold

Table: Frequencies of clinical details amongst the 26 patients on whom the information was available.

\begin{tabular}{|c|c|c|c|c|c|}
\hline Clinical details & Frequency & \multicolumn{4}{|c|}{ High volume culture Small volume culture Bacterial culture } \\
\hline Sample with bacterial pathogens & 18 & 69.2 & 16 & 16 & 7 \\
\hline Symptoms $1-2$ week & 16 & 61.5 & 16 & 14 & 7 \\
\hline Symptoms $>2$ weeks & 7 & 26.9 & 5 & 3 & 0 \\
\hline Antibiotics & 11 & 42.3 & 10 & 9 & 4 \\
\hline Any comorbid & 11 & 42.3 & 10 & 8 & 5 \\
\hline Systemic steroids & 10 & 38.5 & 9 & 9 & 5 \\
\hline Asthma & 9 & 34.6 & 8 & 8 & 3 \\
\hline $\begin{array}{l}\text { Underlying lung disease/ } \\
\text { bronchiectasis }\end{array}$ & 8 & 30.8 & 7 & 5 & 2 \\
\hline Antifungal & 3 & 11.5 & 3 & 3 & 2 \\
\hline Cancer & 3 & 11.5 & 3 & 3 & 3 \\
\hline Diabetes mellitus & 3 & 11.5 & 3 & 2 & 0 \\
\hline Hemoptysis & 3 & 11.5 & 3 & 3 & 1 \\
\hline
\end{tabular}

